\title{
NZ journalism unit standards: Are they still needed?
}

\author{
FRANK SLIGO \\ Massey University
}

$\mathrm{O}$

NE indicator of health in any field of human endeavour is the extent and quality of debate that occurs on how its new and developing practitioners should be educated. Currently in New Zealand a powerful influence upon the subject matter to be taught in professional journalism courses is a set of 'unit standards' comprising part of the National Qualifications Framework accredited by a government agency, the NZ Qualifications Authority (NZQA). These unit standards describe in extraordinary, reductionist detail, the requirements for two national qualifications, the National Diploma in Journalism, and the National Diploma in Journalism (Graduate).

Only one standard-setting body has formal responsibility for these two qualifications, the NZ Journalists' Training Organisation (JTO), a government-mandated industrial training organisation (ITO). One of the major functions of the JTO is to determine the skills that new entrants into the journalism profession should possess prior to their arrival. The JTO is also the primary organisation that has formal input into assessing and moderating how well institutions of higher education teach these unit standards.

It is of concern, however, that although over the years journalism training has increasingly been drawn into the institutions of higher education (mainly polytechnics but including three universities, Auckland University of Technology, Canterbury and Massey) in recent times there appears to have been little professional debate about the appropriateness of an ITO being in the role of gatekeeper and standard-setter for the content of academic programmes 
(one recent exception being Thomas, 2003). The role of any training organisation, after all, is just that, training. This contrasts with the purpose of an institution of higher learning which, while not ignoring training, must transcend it to also encompass education. This paper offers some commentary on the current role of unit standards in journalism education and suggests areas of necessary reform.

\section{Unit standards and training}

Recently I completed a two-day first-aid course run by the Red Cross, and I am now the proud owner of a unit standards based, NZQA-approved certificate attesting I can carry out first-aid functions to a basic level. The course was nearly all what and very little why. However, absolute neophytes like me perhaps didn't need the whys so much as whats, as arguably their most pressing need is a simple, routinised, mechanistic awareness of what to do, when. ABC: $\mathrm{A}=$ airway, $\mathrm{B}=$ breathing, $\mathrm{C}=$ circulation. Do this first, do that next.

At the centre of our activities was a dummy whose name, we were informed, was Bob. Unit standards regulated our behaviour as follows: left hand on Bob's forehead, right hand under Bob's chin. Lift Bob's head back, just to here. Pinch Bob's rubber nose and blow between his rubber lips so his chest rises to there and no further. Under circumstances of this nature, where human performance can be tightly measured and monitored, unit standards may be appropriate.

\section{Competence-based training}

Unit standards derive from a behaviourist philosophy called competencebased training (CBT) (e.g. Carnevale, Gainer \& Meltzer, 1990) that was popular in industrial training circles in the early 1980s. Functionalist in its orientation, CBT has no place for individual differences such as in personal learning styles, and assumes a one-size-fits-all approach to teaching and learning. Just as importantly, CBT is uninterested in the way in which learners successfully become engaged in the creation of new individual knowledge, that is, by learning to think creatively about the subject and exploring issues for themselves.

Instead, CBT distracts educators from attention to in-depth questions of pedagogical quality and does not imbue in learners capability to critically analyse the meaning or relevance of their subject. In a changing world, predetermined unit standards become out of date and so are likely to block 
innovative perspectives or paradigms such as new developments in international best practice. As already noted, at very basic levels of human performance this may be of lesser importance. Yet in any discipline of some complexity, such as journalism, the CBT approach to learning does not engage the learner's intelligence and thus potentially trivialises the field. Over a century ago the American journalist Joseph Pulitzer stated that 'Journalism is, or ought to be, one of the great and intellectual professions' (Herbert, 2003, p. 191) but CBT makes no contribution to this goal.

The appropriateness of a national qualifications framework and unit standards for higher education has been criticised by professionals in the field (e.g., Viscovic, 1999; Strathdee \& Hughes, 2001). Their relevance has also been slated by professional bodies such as the New Zealand Institute of Management (NZIM) which has drawn attention to 'the major gap between the unit standards (for management education) developed by the National Standards Body and the expressed interests and needs of business and educational bodies' (Matheson, 2000: 112). Also in the field of management, the NZIM has stated its concerns about the 'lack of consistency or coverage of unit standards' and 'a rigid adherence to appropriateness of form, wording and definition rather than an appreciation that learning is unique and personal and is not necessarily contingent on a particular form of teaching or assessment' (Matheson, 2000: 113).

\section{Training versus education}

The philosophical basis of CBT and unit standards appears to be the notion that what a trainee needs to absorb, sponge-like, can be encapsulated in a collection of pre-packaged edicts which, once ticked off, represent that appropriate knowledge has been acquired. In fact this is a flawed model of data-transfer, not a theory of education. William Yates rightly said that education is not filling a bucket but lighting a fire. His apothegm draws attention to the potentially inspiring nature of education, and to the way in which learners, once challenged and excited by what they have encountered, can themselves discover previously unthought-of applications of their subject. Such participant-focused discovery learning has of course no part in the rigid and simplistic mindset fostered by CBT and unit standards.

Unit standards further appear to be based on a fundamental confusion about the meaning of the key terms data, information and knowledge, and their implications for education. Modern definitions generally represent the differ- 
ences among them along the following lines. Data are potentially machinereadable 'factual' elements, the meaning of which may find general agreement among differing observers. Information is more complex, and is created from data at the point where it is accessed by a human being. This always involves some conversion and interpretation of that data into a form that is meaningful to the individual concerned. Because with information there is an element of individual interpretation, its emphasis and significance will differ among people.

Knowledge, however, is unique to the human being processing it. While people create their knowledge not least from data sources accessible to others, a person's final knowledge about a topic of any complexity is always and necessarily distinct from the knowledge possessed by other people. And it follows that the greater the differences (cultural, social, economic, religious, geographical etc.) existing among individuals, the greater the distinctions among the knowledge-sets that they have created and which shape their lives.

The problem in all this for unit standards is that while they often purport to prescribe outcomes at the level of knowledge, in fact, they are best at dealing with data, unambiguous 'facts' on which varying observers can agree. Therefore whenever unit standards start to venture into realms that are contested, complex or controversial, which require human knowledge, judgement and insight, immediately contradictions occur. A credibility gap then opens between the data-based, prescriptive world of unit standards, and the subtle and exacting knowledge required by real-life professionals. Essentially this is why the universities normally have declined to be involved with unit standards, on account of their oversimplifications of how they represent reality.

A further weakness of unit standards is their focus on the minutiae of taught content rather than what people learn. By ignoring the learner, the possibilities of individual excellence are seen as irrelevant. Unit standards are indifferent to the unique and personal nature of a person's learning and so are disconnected from the real world of what people actually get from their learning experience. In contrast to unit standards, good educators know that they should not try to teach their students everything, but their more important role is to guide students in the search for knowledge and insights.

\section{University research and research-led teaching}

As we are frequently told, New Zealand is becoming closely integrated within an international economy. Yet our higher education system has always been 
oriented to its place in the international sphere, and the most respected parts of our university systems have sought to pursue high-level research of international standing. Now, more than ever in higher education, we are exposed to exacting international competition, usually from institutions better-resourced than ourselves. Universities understand that their international reputation rests upon their research, of which research-led teaching forms a part. Yet pressures are currently being intensified under NZ's new academic funding mechanism, Performance Based Research Funding (PBRF), with universities now being ranked both nationally and internationally by their research quality. Overseas experience suggests that international students are attuned to international rankings in deciding where to study.

Research-led teaching means that academics, whether singly or collectively, must subject their own pedagogical practices, including subject matter and bodies of knowledge, to rigorous and on-going scrutiny to determine how well they meet learners' needs. In this process there must be neither fear nor favour; no privilege may be accorded to anyone's model of what a given subject should or should not contain.

The risk for journalism education is that attempts to confine it to unit standards and thus divorce it from research-led teaching, must undermine its international standing and therefore its usefulness to students, given that the perceived quality of any student's course is aligned to the international reputation of their university. Any disciplinary area that seeks to be recognised as a leader, whether within its own institution, nationally, or internationally, will have little prospect of doing so under a unit standards model.

\section{Academic freedom}

What does academic freedom mean? This is a term not much heard in recent times as state intervention in New Zealand's higher education has gradually intensified via mechanisms such as PBRF. No freedom is absolute of course, and any freedom will exist within a framework of duties and mutual expectations of various kinds. Nevertheless, academic freedom is still fundamental to the university's legislatively-mandated requirement to serve as the critic and conscience of society.

Essentially, academic freedom, as interpreted in respect of teaching practice in Massey's Department of Communication and Journalism, means the right of staff members to determine individually and collectively three things: what shall be taught in a given course, how that material shall be taught, 
and how students' learning shall be assessed. Should teachers concur that unit standards-based material such as for journalism is indeed appropriate for academic purposes, then there will be a happy coincidence of aims. But if they determine that unit standards are inadequate, then it is not only their right but their duty to find better alternatives.

For reasons of academic freedom, the Department of Communication and Journalism will not mandate that unit standards must or must not be taught. Journalism staff are as free to select from this material in their learning and teaching design as from any other potential source. But journalism staff are encouraged to critique the New Zealand Journalism unit standards in the light of their relevance to the 21 st century media environment.

So far I have addressed the philosophical problem of the misfit between unit standards and in-depth education. However, a pressing practical problem with unit standards is that if they are applicable anywhere, it will be in a context where individuals' behaviour can actually be measured in a way on which observers can agree. In the earlier example of a first aid course, many of the unit standards were measurable, hence potentially may be valid. The expansion of Bob the dummy's chest could be observed, and the trainee advised that their breath was too little, about right, or too much. This kind of simple assessment is not possible within the intricacies of organisational behaviour in the modern workplace.

Realistically, there is no point in specifying the minutiae of work actions, unit standards-style, in a newsroom (or any other complex work environment), given that management and staff activity do not come out of a rule-book, but instead are formed by the need to achieve organisational goals as defined by management and as modified by acculturation and interactional norms. That is, in everyday reality, people at work behave according to what they observe is or is not accepted practice in their particular enterprise, and especially as modelled by its most senior personnel. Therefore the attempt of unit standards to legislate in an area where actual measurements cannot be taken and where organisational culture shapes behaviour anyway, makes them irrelevant to practitioners and educators alike.

Ultimately, journalism unit standards, although deriving philosophically from the CBT approach, comprise a poor example of it. CBT may have a place in curriculum design when its elements can be unambiguously specified and genuine measurement can be carried out. However, in professional education, such specifications tend to be uncommon.

196 PACIFIC JOURNALISM REVIEW 10 (1) 2004 
Lee Bollinger, President of Columbia University, rightly observes that "Journalism has an ascending importance in the modern world, and more than at any time in human history the character of the press is a key determinant shaping and defining national and global society" (2003). In my view, journalism has too important a role within a modern democracy and in the shaping of civil society to be confined by unit standards. The quality of public debate and public understanding of major current issues are closely linked to the quality of debate fostered in a free press. One purpose of higher education is to provide the conditions under which students can improve their ability to think (and arguably this is the critical goal even for primary and secondary education). Unit standards offer no mechanisms by which this may proceed.

\section{What unit standards may contribute}

Although this paper criticises the place of unit standards in journalism and in higher education generally, some of their characteristics will contribute to a reformed curriculum. First, unit standards were established in the 1990s as a means of specifying minimum standards for taught content within a diverse and uneven array of New Zealand journalism training programmes. Even if unit standards are not appropriate for this purpose, agreement by educators to the extent possible on a relevant body of knowledge, along with on-going relationships with relevant industry bodies such as the JTO, will strengthen the connection between practitioners and education professionals.

A second redeeming element in unit standards is their practice orientation. Any quality journalism programme will necessarily be based on media realities and so could use the craft intelligence embodied in the unit standards as a starting point.

Third, unit standards in journalism were designed in an attempt to form a compendium of what comprises journalistic work. As such they indicate a commitment to a body of knowledge and so create a platform upon which attempts to construct a more appropriate curriculum could be based.

\section{Issues for journalism education}

A re-think of journalism education could arrive at an approach along the following lines. First, journalism education should provide for discoverybased learning, so that students can themselves determine how and when they access that body of knowledge pertaining to journalism. Students should be aware that knowledge pertaining to journalism exists and that they will be 
examined on it, but the processes of their study should be largely of their own choosing.

Second, students on a professional journalism course, as opposed to a news media or media studies course, should be taught mainly by experienced journalists. This is required, for example, in Massey University's Department of Communication and Journalism. It is important for such individuals to facilitate students' learning and to explain contextual issues within the ambit of New Zealand and global news media environments. As ever, the most powerful and productive interaction between student and teacher occurs when the Socratic model is employed. The role of the teacher employing maieutic logic is certainly not primarily to utter facts in unit standards mode, but instead is to ask the most apposite questions that get to the nub of the matter, to know when to encourage, when to provoke, when to persuade, when to be silent. In a rapidly-changing media world, a pressing need is for journalists who are well-informed about the everyday realities of the world, who have learned how to ask the right questions, and who have the skills of writing the right piece at the right time for the right publication.

Third, journalism students must write and edit, write and edit, until they know how to produce a well-honed article in the minimum time. Journalism students in the Massey programme, for example, must produce a large output of published pieces in their one-year course. Some other journalism schools put more emphasis on 'publishable' rather than published items. Admittedly all or virtually all of our students are already university graduates and so will understand the requirement to write and have some abilities in this regard. Nevertheless the requirement to publish virtually every week of their study provides a stretch target for students, and an effective means to build their practical writing experience and self-confidence as writers.

Taken together, the steps of mandating discovery-based learning and learner-centred pedagogy, employing as lecturers people with hard journalistic experience, from whatever form of media, and setting exacting writing targets for publication, will combine to produce a meaningful and valuable learning experience for students. 


\section{References}

Bollinger, L.C. (2003). The future of journalism education. www.columbia.edu/cu/president/communications\%20files/ futurejournalismeducation.htm (Accessed 31 March 2004).

Carnevale, A., Gainer,L.\& Meltzer, A. (1990). Workplace basics: The essential skills employers want. San Francisco: Jossey-Bass.

Herbert, J. (2003). Industry and academics: We need each other's research. Australian Journalism Review, 25 (2): 189-205.

Matheson, D. (2000). Ensuring the right training. Management (NZ) December, pp 112-113.

NZ Journalism Unit Standards. 3 April 2004.

Strathdee R. and Hughes D. (2001). The National Qualifications Framework and the discouraged worker effect. New Zealand Journal of Educational Studies 36 (2): 155-169.

Thomas, R. (2003). The Place of Unit Standards in Journalism Education of the Future. Paper presented at JEANZ Conference, 2003.

www.jeanz.org.nz/Conference\%202003\%20Ruth\%20Thomas.htm (Accessed 16 March 2004).

Viskovic, A. R. (1999). Student-centred learning: Does the New Zealand National Qualifications Framework promote self-directed learning? HERDSA Annual International Conference Proceedings, Melbourne, 12-15 July.

http://herdsa.org.au/branches/vic/Cornerstones/authorframeset.html (Accessed 25 February 2004).

Associate Professor Frank Sligo is Head of the Department of Communication and Journalism, Massey University.

F.Sligo@massey.ac.nz 


\section{Christchurch hosting Jeanz Conference 2004}

Theme: "The practice of journalism in an increasingly diverse society"

The New Zealand Broadcasting School in Christchurch will host the Journalism Education Association of New Zealand (Jeanz) conference this year.

The two-day conference will run in late November/early December. The date will be confirmed soon and will not clash with the JEA Conference in Fiji.

A call for papers will be issued in July.

Check the Jeanz website for updates on conference details.

The site also carries news from New Zealand journalism schools as well as archives of Jeanz conference papers.

\section{Journalism Education Association of New Zealand (Jeanz)}

www.jeanz.org.nz 